\title{
Eş Zamanlı Topla-Dağıt Döngüsel Dağıtım Modeli ve Endüstriyel Bıçak Bileme Fabrikası Örnek Uygulaması
}

\author{
Cemal Kazım GONCA ${ }^{1 *(D)}$, Bahadır GÜLSÜN ${ }^{2}$ (D) \\ ${ }^{1}$ Graduate Student, Yıldız Teknik University, Mechanical Faculty, Department of Industrial Engineering, \\ İstanbul, Turkey \\ ${ }^{2}$ Assoc. Prof. Dr., Yıldız Teknik University, Mechanical Faculty, Department of Industrial Engineering, \\ İstanbul, Turkey
}

Geliş Tarihi/Received: 14.10.2019

Kabul Tarihi/Accepted: 01.02.2020
Doi: doi.org/10.31200/makuubd.633052

Araştırma Makalesi/Research Article

\section{ÖZET}

Giderek artan küresel rekabet ortamında şirketler, tedarik zinciri süreçlerini en verimli ve etkin şekilde yönetmek için çeşitli yöntemlere başvurmaktadır. Bu konuda önemli yöntemlerden biri dağıtım ağlarının doğru tasarlanması yönündedir. Dağıtım ağı tasarımında önemli bileşenler tesislerin yer seçimi ve araçların rotalanmasıdır. Mümkünse, dağıtım maliyetini en aza indirmek amacıyla, yer seçimi ve rotalama problemindeki iki karar beraber dikkate alınmalıdır. Ancak, pratikte birçok sektörde yer seçimini etkileyen çok daha farklı ve ağırlığı fazla faktörler bulunabilmekle beraber, zamanla değişen ihtiyaçlar rotalama noktalarının değişmesine neden olabilmektedir. Ayrıca bu çalışmanın başlangıçta yapılmadığı durumlarda, yer değiştirme maliyeti çok daha yüksek olacağı için, çalışmalar sadece rotalama problemi olarak ele alınabilmektedir.

Araç rotalama problemi, bir veya birkaç noktadan, belirli müşterilere ürün dağıtımı veya toplanması olarak tanımlanabilir. Bu problemlerde, araç kapasiteleri ve müşterilerin servis süresi gibi kısıtlar dikkate alınarak etkin kullanım hedeflenmektedir. Araç rotalama problemleri, birçok alanda gerçek hayatta karşılaşılan problemlerdir. Bu durum bu konuda çalışmalar yapılmasını ve verimli sonuçlar ortaya koyan algoritmalar sunulmasında fayda sağlamıştır.

Bu çalışmada ise, karşılaşılan problemin çözüme ulaşması adına, model eş zamanlı topla-dağıt döngüsel araç rotalama problemi olarak kurgulanmıştır. Eş zamanlı topla-dağıt döngüsel araç rotalama problemi; müşterilerin dağıtım ve toplama taleplerinin, başlangıç ve bitiş noktaları

E-mail/e-ileti: kazimgonca@gmail.com 


\title{
Gonca, C. K. \& Gülsün, B.
}

aynı (işletme) olacak şekilde araçlar için belirli bir rota belirlenerek eş zamanlı olarak karşılandığı bir problemdir. Bu çalışma kapsamında, endüstriyel bıçak bileme fabrikası üzerinden 8 farklı şehirde 20 müşteriye lojistik hizmet oluşturulması üzerine rotalama problemi ele alınmıştır. Probleme konu olan şirket, mevcutta var olan yöntemde ürün lojistiği kargo firmaları ile sağlanmaktadır. Maliyetleri düşürmek adına şirketin kendi lojistik ağının kurulması üzere çalışma yapılmıştır. Bu çalışmada, minimum sayıda araç kullanımı ile toplam kat edilen mesafenin minimumda tutulması ile birlikte, kısıtlar göz önüne alınarak, minimum maliyet hedeflenmiştir. Problem çözümü için doğrusal programlama kullanılmış ve GAMS üzerinden çözüme ulaşılmıştır.

Anahtar kelimeler: Dağıtım Ağları, Araç Rotalama, Döngüsel Araç Rotalama, Eş Zamanlı Topla Dağıt Döngüsel Araç Rotalama.

\section{Application of Vehicle Routing Problem with Simultaneous Pickup and Delivery}

\begin{abstract}
In an increasingly global competitive environment, companies use a variety of ways to manage their supply chain processes in the most efficient and effective manner. One of the important methods is to design the distribution networks correctly. Important components in the distribution network design are the location selection of facilities and routing of vehicles. Where possible, two decisions in site selection and routing should be considered together to minimize the cost of distribution. However, in practice, there are many different and weighty factors that affect the choice of place in many sectors, but the changing needs over time may lead to changing routing points. In addition, in the absence of this study at the beginning, since the cost of displacement will be much higher, only studies can be considered as routing problem.

Vehicle-routing problem can be defined as product distribution or collection to specific customers from one or several points. In these problems, effective use is aimed by taking into consideration the constraints such as vehicle capacities and customer service time. Vehicle routing problems are real life problems in many areas. This situation has been beneficial in carrying out studies on this subject and presenting algorithms that yield productive results.
\end{abstract}

To solve the problem encountered in this study, the model was created as a vehicle routing problem with simultaneous pickup and delivery. Vehicle routing problem with simultaneous 
pickup and delivery; It is a problem that the distribution and collection demands of the customers are met simultaneously by setting a specific route for vehicles with the same starting and ending points (firm). Within the scope of this study, routing problem on creating logistics services for 20 customers in 8 different cities over the factory was discussed. The company that is the subject of the problem is provided by the cargo logistics companies in the present case. In order to reduce costs, efforts were made to establish the company's own logistics network. The aim of this study is to keep the total distance traveled to a minimum by using the minimum number of vehicles, and to minimize the costs. Linear programming was used for problem solving and the solution was reached via GAMS.

Keywords: Distribution Networks, Vehicle Routing, Cyclic Vehicle Routing, Vehicle Routing Problem with Simultaneous Pickup and Delivery.

\section{GIRIŞ̧}

Küresel piyasalarda giderek artan rekabet, teknolojinin hızlı gelişmesi, trendlerin hızlı değişmesinden kaynaklı kısa yaşam eğrisi bulunan ürünler ve bunlar karşısında sürekli değişen ve artan müşteri beklentileri, yasal ve çevresel sorumluluk gibi nedenler, şirketlerin dağıtım sistemlerine önem vermesine, yatırım yapmasına ve en verimli şekilde kullanması durumunda bırakmıştır. Bu durumda da araç rotalamasında sürekli gelişime ihtiyaç duyulmuştur.

Araç rotalama problemleri, lojistik alanında önemli bir problemdir. Tipik bir araç, rotalama problemi; bir depo, fabrika, işletme gibi dağıtım noktasından, şehirler, mağazalar, depolar, müşteriler gibi dağılmış farklı noktalara, en düşük maliyetli rotaların belirlenmesi problemidir. Her bir rota, her noktanın bir araç tarafından mutlaka ziyaret edildiği, tüm rotaların dağıtım noktasında başlayıp bittiği ve her bir rotadaki toplam talebin, bu rota için belirlenen araç kapasitesini aşamadığı şekilde oluşturulmalıdır.

Araç, rotalama problemi 50 yıla yakın bir zamandır çalışılmaktadır. Bu problem ilk olarak Dantzig ve Ramser tarafından 1959 yılında çalışılmıştır. Clarke ve Wright 1964 yılında Dantzig ve Ramser'in metodunu geliştirmiş, ve klasik tasarruf metodunu önermişlerdir. Bundan sonra araç rotalama probleminin değişik çeşitlerine çözüm bulmak için yüzlerce farklı model ve algoritma önerilmiştir. Uygulama alanının çokluğu ve problemin ilginç, olmasından dolayı araç rotalama problemi pek çok araştırmacının ilgisini çekmiştir (Düzakın ve Demircioğlu, 2009). 


\section{Gonca, C. K. \& Gülsün, B.}

Gün geçtikçe ürün dağıtımında çeşitlik artmakla beraber bazı sık karşılaşılan problemler şunlardır (Düzakın ve Demircioğlu, 2009);

- Ürün ve hizmetlerin bir veya daha fazla sayıdaki depodan, çeşitli müşteri yerlerine dağıtımı,

- Üretim planlaması ve hammadde, yarı mamul ve mamullerin fabrikalar arası taşınması,

- Stok planlaması ve ürünlerin satış, yerlerine sevkiyatı,

- Havayolu şirketleri ile yolcu ve ürün taşınması,

- Bar ve lokantalara içecek dağıtımı,

- Para dağıtımı,

- Benzin ve mazot dağıtımı,

- Süt dağıtımı ve toplanması,

- İnternetten yapılan alışverişlerin teslimatı,

- DVD film kiralama hizmeti,

- Çöp toplanması ve taşınması,

- Ana depodan mağazalara ürün dağıtılması,

- Posta hizmetleri

Araç rotalama problemleri, kısıtlara ve pratik hayattaki uygulama alanlarına göre çeşitli şekillerde sınıflandırılmıştır. Problemlerde yaygın kullanılan ve literatürde topla-dağıt araç, rotalama problemi olarak geçen yöntemde, her rotanın depoda başlayıp depoda bittiği, her müşteriye bir aracın gittiği; rotanın toplam talebinin araç, kapasitesini aşmadığı, her müşterinin arz ve talebinin karşılandığı problemlerdir (Çetin ve Gencer, 2010). Pratikte birçok örneği bulunan topla-dağıt araç, rotalama problemi, araç, rotalama probleminin genelleştirilmiş bir halidir. Sağlık sisteminde, kanların merkezlerden hastanelere dağıtımı esnasında toplama kamplarından merkeze yeni kanların getirilmesi; otomotiv sektöründe, yedek parçaların bölge bayilerine dağıtımı esnasında kullanılmış, parçaların geri dönüşüm için fabrikalara geri gönderilmesi; gıda sektöründe, günlük taze ürünlerin marketlere dağıtımı esnasında günü geçmiş, ve bozulmuş, ürünlerin geri toplanması, topla-dağıt araç, rotalama problemlerine örnek olarak verilebilir (Karaoğlan, 2009). Bu problem, toplama ve dağıtım faaliyetlerinin gerçekleştirilmesine göre üç, sınıfa ayrılmaktadır (Atmaca, 2012).

- Önce dağıtım sonra toplama,

- Karışık dağıtım toplama,

- Eş zamanlı dağıtım ve toplama 
Önce dağıtım sonra toplama araç, rotalama problemlerinde; dağıtım noktasından farklı noktalara dağıtılacak malzemelerin tamamı dağıtıldıktan sonra hedef noktalardan dağıtım merkezine geri gönderilecek malzemelerin toplama işlemi yapılır. Müşterilere birden fazla kez uğranabilir.

Karışık dağıtım toplamalı araç, rotalama problemlerinde; dağıtım ve toplama işlemi karışık olarak yapılmaktadır. Müşterilere birden fazla kez uğranabilir.

$\mathrm{Bu}$ çalışmanın konusu olan, eşzamanlı topla-dağıt araç, rotalama problemidir. Eş zamanlı dağıtım ve toplama yapılan araç, rotalama problemleri, bir veya birden fazla dağıtım noktasından sağlanan malzemenin, araçlara yüklenerek talep noktalarına ulaştırılmasını, talep noktalarından da geri gönderilecek malzemenin, araç, hedef noktaya uğradığı anda aynı araca yüklenerek, araçların gittiği toplam yolu minimize edecek şekilde, dağıtım noktasına geri gönderilmesini sağlayacak şekilde araç, rotalarını oluşturmayı hedefler (Göksal vd., 2013).

\section{LITERATÜR ARAŞTIRMASI}

Bu bölümde, araç rotalama problemi ve topla-dağıt araç rotalama problemlerinin ortaya çıkışına dair araştırmalara yer verilmiştir (Karaoğlan, 2009; Yazgan ve Büyükyılmaz, 2017; Bayrak ve Özyörük, 2017).

Araç, rotalama problemlerinin matematiksel modeli ve çözüm yaklaşımı literatürde ilk olarak 1959 yılında Dantzing ve Ramser tarafından yapılmıştır (Dantzig ve Ramser, 1959). Müşterilerden dağıtım noktalarına geri toplamanın da gerektiği topla-dağıt araç rotalama problemleri için literatürde yapılan ilk çalışmalardan biri 1996 yılında Toth ve Vigo tarafından yapılmıştır (Toth ve Vigo, 2002). Bu problem tipi önce dağıtımın daha sonra toplamanın yapıldığı, dağıtım ve toplamanın karışık olarak yapıldığı, dağıtım ve toplamanın eş zamanlı olarak yapıldığı modeller olarak ayrılarak her bir model için çözüm yaklaşımları geliştirilmiştir (Salhi ve Nagy, 1999; Min vd., 1992). Dağıtım ve toplamanın eş zamanlı olarak yapıldığı modeller ilk defa Ohio'da halk kütüphanelerine kitap, film, kutu gibi materyallerin dağıtılıp toplanması ile ilgili bir çalışmada kullanılmıştır (Min, 1989). Salhi ve Nagy tarafından yapılan bir çalışmada, eş zamanlı topla-dağıt araç rotalama problemleri için eklemeye dayalı sezgisel algoritmalar önerilmiştir (Salhi ve Nagy, 1999). 2001 yılında Dethloff (2001), Casco vd. (1988) tarafından önerilen alt tur genişletme kriterini eş zamanlı problem yapısına uyarlayarak, eş zamanlı dağıtım ve toplama yapılan araç, rotalama problemleri için bir matematiksel model ve ekleme stratejisine dayalı bir kurucu sezgisel algoritma geliştirilmiş, en ucuz ekleme, artık 


\section{Gonca, C. K. \& Gülsün, B.}

kapasite gibi dört farklı ekleme kriterinin algoritmanın performansı üzerindeki etkisi incelenmiştir (Dethloff, 2001).

Bir diğer matematiksel model ve eklemeye dayalı sezgisel algoritma ise Nagy ve Salhi (2005) tarafından önerilmiştir. Önerilen algoritmada uygun olmayan (araç, kapasitesini aşan) rotalardan uygun rotaları elde etmek amacıyla araç rotalama problemleri için önerilen yaklaşımlar eş zamanlı dağıtım ve toplama yapılan araç, rotalama problemlerine uyarlanarak kullanılmıştır. Tang ve Galvao (2002) tarafından yapılan bir çalışmada ise kapasite kısıtlı araç rotalama problemi için geliştirilen tur parçalama ve süpürme algoritmaları, eş zamanlı dağıtım ve toplama yapılan araç, rotalama problemleri için uyarlanmıştır.

\section{UYGULAMA: EŞ ZAMANLI TOPLA-DAĞIT DÖNGÜSEL DAĞITIM MODELININN BİR FİRMADA ÖRNEK UYGULAMASI}

Endüstriyel bıçak bileme fabrikasında döngüsel dağıtım modeli ile müşterilerden parça toplama ve müşterilere parça dağıtma konusu ele alınmıştır.

Bu uygulamada, Aydın'da faaliyet gösteren bir endüstriyel bıçak bileme fabrikasının müşteri ağı modellenmiştir. İşletme Türkiye'de çok sayıda ve farklı noktalarda müşteriye sahiptir ve bu müşterilerden belirli aralıklarla bilenmek üzere teslim alınan farklı ürün çeşitleri bulunmaktadır. Müşteriler, ahşap, plastik ve metal işleme endüstrisinde yer almaktadır. Mevcutta, en çok siparişi olduğu 8 şehirde müşterisi bulunan işletmenin, lojistik sistemi ise mevcutta kargo ile sağlanmaktadır.

Müşteriler, işlenmesini istediği ürünü kargo ile fabrikaya ulaştırmaktadır. Fabrika işlenen ürünü tekrar kargo ile müşteriye yollamaktadır. Müşterilerin ahşap, plastik veya metal işlemek için kullandığı bıçakların belirli bir ömrü olmakla beraber, kullanım sıklığına bağlı olarak belirli aralıklarla bileme işlemi yapılması gerekmektedir. Genel itibariyle, belirli ve düzenli bir kullanım sağlandığı için, düzenli olarak haftalık, aylık gibi belirli periyotlarda bileme ihtiyacı doğmaktadır. Bu gibi durumlar için müşteriler, bıçakların yedeğini bulundurmakta ve her ürün tesliminde diğer bıçak teslim alınmaktadır. Bazen kargo hatası durumlarında, erken/geç teslimler olabilmekte bu da planlamayı ve teslim süresini etkilemektedir. Ayrıca ek maliyetler oluşmakta ve müşteri memnuniyeti de olumsuz etkilenmektedir. Belirtilen sorunları ortadan kaldırmak veya etkisini azaltmak, süreci daha verimli hale getirmek amacından yola çıkarak uygulama ele alınacaktır. Bu uygulamanın amacı, 
problemin tanımı, probleme çözüm olacak amaca uygun olarak modelin kurulumu ve çözümüne dair bilgiler paylaşılacaktır (Yürek, 2012).

\section{1. Örnek Uygulamanın Amacı}

Fabrikanın ürün lojistiği daha önce açıklandığı gibi kargo firmalarınca sağlanmaktadır. Müşteriler planlanmamış zamanlarda farklı ürünleri kargoya verebilmektedir. Fabrika ayrıca kargo firmalarına yaptıkları taşıma için lojistik bedeli ödemektedir. Konuya bahis ürünler yani bıçaklar genel itibariyle ebatları büyük, ağırlıkları fazla ürünlerdir. Ayrıca birçoğunun kırılganlığı fazla olduğu için hassas ürün olarak ele alınmakta ve bu durum taşıma maliyetlerini artmaktadır.

$\mathrm{Bu}$ uygulamanın amacı fabrikanın tedarik ağını kargo firmalarından kurtarıp, organizasyon için tam zamanında felsefesine uygun bir ağ tasarlanmasıdır. Ağın tasarımı problemin yapısı ve bileşenlerine göre değişiklik gösterebilecektir. Uygulamada fabrika ve müşteriler arasındaki taşımanın sorumluluğunu kargo firmalarından alıp fabrikaya verecek bir sistem tasarlanması; bunun mevcut uygulamada yaşanan problemleri azaltması ve maliyetlerde de düşüş sağlaması amaçlanmaktadır.

\subsection{Problem Tanımı}

Çözülmeye çalışılan problem birden fazla müşteriden ürünleri teslim alarak ve ürünleri teslim ederek, fabrika planlamasının doğru sağlanmasını ve teslimat sürelerinin tahmin edilebilir düzeyde olmasını sağlamaktır. Tam zamanında felsefesine uygun çalışmak için müşterilerle mümkün olduğunca fazla seferde temasta olmak gerekmektedir.

Fabrika belirli periyotlarla, organize edilen küçük ve büyük kamyonetlerle müşterileri dolaşarak ihtiyaç duyulan sıklığa göre gereken miktarda ürünleri toplayıp işleme almalıdır. Bu nedenle ihtiyaca göre hesaplanan ürünü almaya yetecek kadar seferde belirli bir rota üzerinde dolaşan kamyonet her uğradığ 1 müşteriden belirlenecek ürünleri teslim alır ve teslim eder. Taşımacılıkla bu şekilde rotalama yapmaya eş zamanlı topla-dağıt döngüsel dağıtım modeli adı verilmektedir.

Eş zamanlı topla-dağıt döngüsel dağıtım problemi kurulurken öncelikle uğranacak noktaları yani müşterileri belirlemek gerekmektedir. Bunu seçerken, müşterinin yerleri, bıçak tipi ve bıçaklarını bileme ihtiyacı sıklığı dikkate alınmaktadır. Bu sıklığa göre periyotlar yani 
haftalık taşıma miktarı belirlenmektedir. Bu bilgilere göre kamyonet tipi ve adedi netleştirilir. Bu bilgiler döngüsel dağıtım probleminin girdisini oluşturacaktır.

\subsubsection{Müşteriler}

Fabrikanın mevcutta, en çok sipariş aldığı 8 farklı şehirde, 20 adet müşterisi bulunmaktadır. Problemi basitleştirmek için, sadece yoğun talebin olduğu şehirler probleme konu edilmiştir.

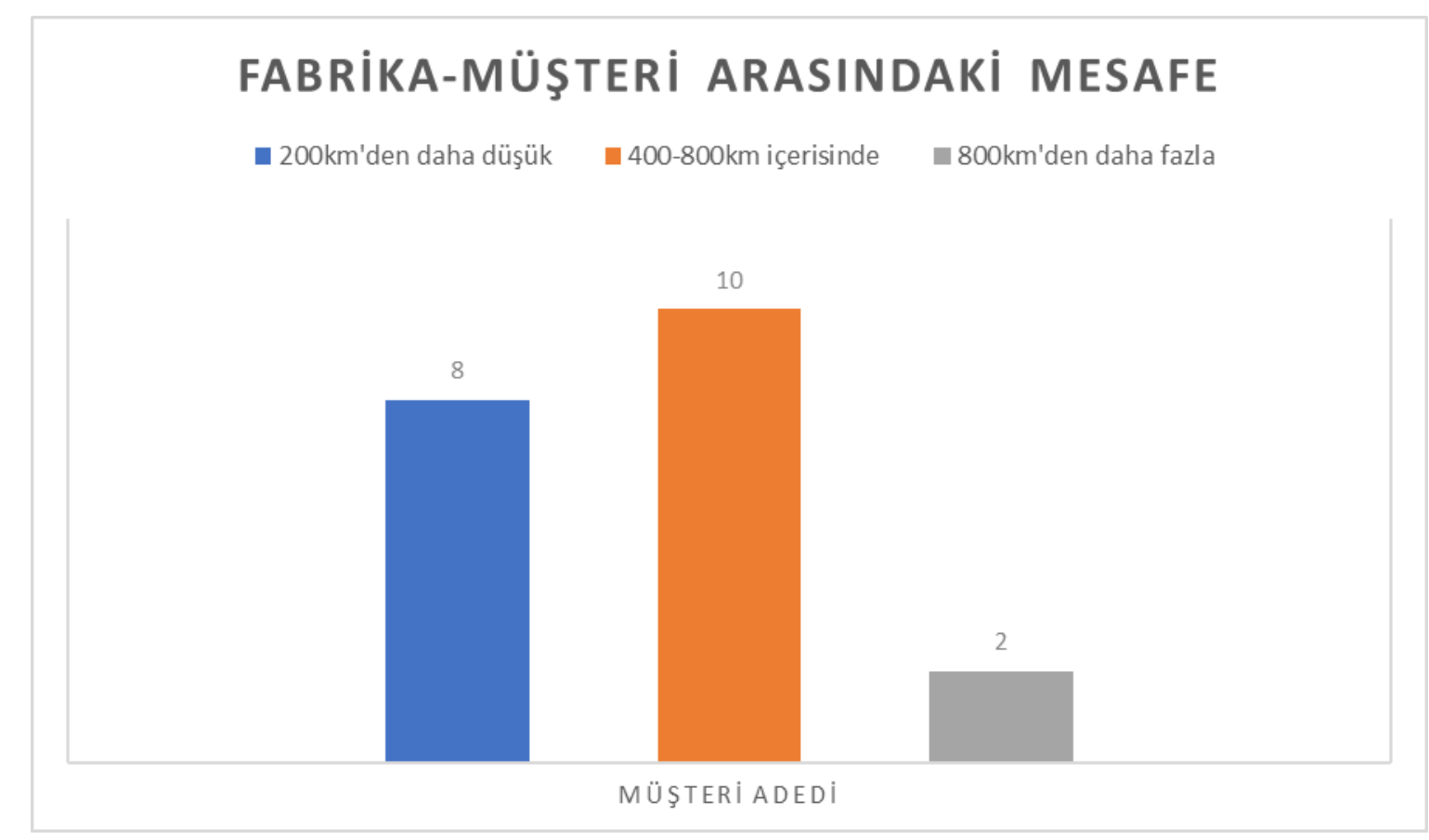

Şekil 1. Müşteriler ile fabrika arasında mesafe grafiği

Bir şehirde birden fazla müşteri bulunmaktadır. Ancak bu uygulamada aynı şehirde olan müşterilerin arasındaki mesafe göz ardı edilmiştir. Müşteriler şehir adı altında toplanmıştır ve şehir olarak anılacaktır. Eldeki veriler değerlendirildiğinde, müşterinin bulunduğu şehir bilgisi ve fabrikaya gönderdiği ürünlerin haftalık bazda değerlendirilmesi sonrası oluşan kargo maliyet bilgileri Tablo 1'de verilmiştir. 
Tablo 1. Ürünlerin taşınmasının haftalık çevrimde yarattığı maliyet

\begin{tabular}{|c|c|c|c|}
\hline İller & $\begin{array}{c}\text { Tip 1 Kargo } \\
\text { Maliyeti (Haftalık) }\end{array}$ & $\begin{array}{c}\text { Tip 2 Kargo } \\
\text { Maliyeti (Haftalı) }\end{array}$ & $\begin{array}{c}\text { Toplam Kargo Maliyeti } \\
\text { (Haftalık) }\end{array}$ \\
\hline Kastamonu (1) & $3.120 \mathrm{TL}$ & $1.200 \mathrm{TL}$ & $4.320 \mathrm{TL}$ \\
\hline Kocaeli (2) & $960 \mathrm{TL}$ & $1.540 \mathrm{TL}$ & $2.500 \mathrm{TL}$ \\
\hline İstanbul (3) & $1.050 \mathrm{TL}$ & $560 \mathrm{TL}$ & $1.610 \mathrm{TL}$ \\
\hline Samsun (4) & $1.375 \mathrm{TL}$ & $840 \mathrm{TL}$ & $2.215 \mathrm{TL}$ \\
\hline Adana (5) & $1.410 \mathrm{TL}$ & $1.440 \mathrm{TL}$ & $2.850 \mathrm{TL}$ \\
\hline Kayseri (6) & $1.645 \mathrm{TL}$ & $800 \mathrm{TL}$ & $2.445 \mathrm{TL}$ \\
\hline Ankara (7) & $750 \mathrm{TL}$ & $300 \mathrm{TL}$ & $1.050 \mathrm{TL}$ \\
\hline Sakarya (8) & $1.120 \mathrm{TL}$ & $660 \mathrm{TL}$ & $1.780 \mathrm{TL}$ \\
\hline TOPLAM & $11.430 \mathrm{TL}$ & $7.340 \mathrm{TL}$ & $18.770 \mathrm{TL}$ \\
\hline
\end{tabular}

Fabrika-Müşteri tedarik sisteminde; mevcut sistemde müşteriler kargo ile ürünleri fabrikaya yollamaktadır. İşlemi tamamlanan ürünler tekrar müşteriye yollanırken, müşteri diğer bıçakları tekrar fabrikaya yollamaktadır. Tasarlanan sistemde ise fabrika kendi araçları ile işlemi tamamlanan ürünleri teslim ederken aynı zamanda işlem ihtiyacı doğan ürünleri müşterilerden toplayacaktır.

Belirlenen müşterilerin fabrikaya olan uzaklığını gösteren taşıma matrisi tablosu Tablo 2 'de sunulmuştur. Şehir “0” fabrikanın bulunduğu Aydın şehridir.

Burada dikkat edilmesi gereken konu araç, toplama-dağıtım planı yapılırken, müşterilere uğrama gerekliliği frekansının hesaplanmasıdır. Bu çalışmada, çevrimler haftalık olarak hesaplanacaktır.

Tablo 2. Fabrika (0 Aydın) ve şehirler (müşteriler) arasındaki mesafe matrisi (km)

\begin{tabular}{|c|c|c|c|c|c|c|c|c|c|}
\hline & $\mathbf{0}$ & $\mathbf{1}$ & $\mathbf{2}$ & $\mathbf{3}$ & $\mathbf{4}$ & $\mathbf{5}$ & $\mathbf{6}$ & $\mathbf{7}$ & $\mathbf{8}$ \\
\hline $\mathbf{0}$ & 0 & 844 & 573 & 684 & 1018 & 874 & 830 & 597 & 605 \\
\hline $\mathbf{1}$ & 844 & 0 & 396 & 507 & 290 & 683 & 453 & 236 & 359 \\
\hline $\mathbf{2}$ & 573 & 396 & 0 & 111 & 623 & 837 & 663 & 342 & 37 \\
\hline $\mathbf{3}$ & 684 & 507 & 111 & 0 & 734 & 948 & 774 & 453 & 148 \\
\hline $\mathbf{4}$ & 1018 & 290 & 623 & 734 & 0 & 721 & 453 & 413 & 586 \\
\hline $\mathbf{5}$ & 874 & 683 & 837 & 948 & 721 & 0 & 335 & 492 & 800 \\
\hline $\mathbf{6}$ & 830 & 453 & 663 & 774 & 453 & 335 & 0 & 335 & 626 \\
\hline $\mathbf{7}$ & 597 & 236 & 342 & 453 & 413 & 492 & 335 & 0 & 305 \\
\hline $\mathbf{8}$ & 605 & 359 & 37 & 148 & 586 & 800 & 626 & 305 & 0 \\
\hline
\end{tabular}

Kaynak:http://www.kgm.gov.tr/SiteCollectionDocuments/KGMdocuments/Root/Uzakliklar/ilmesafe.xls

\subsection{2. Ürünler}

Bıçak taşımada kullanılan kutu tipleri parça tiplerine ve özellikle ebatlarına göre çeşitlilik göstermekte ve bir standardı olmamakla beraber, genel olarak sektörde kullanılan 


\section{Gonca, C. K. \& Gülsün, B.}

kutular benzerdir. Ahşap olarak tercih edilen kutular, bıçakların kırılgan yapıda olmasından dolayı, yüksek dikkatle paketlenir ve taşınır. Bu çalışmayla beraber işletme sahipliğinde standart tip kutu kullanılacaktır. Kullanacak kutu farklı ebattaki bıçaklar için 2 farklı ebat olarak belirlenmiştir. Tip $130 \mathrm{~cm}$ x $30 \mathrm{~cm}$ x $15 \mathrm{~cm}$ ebatlarında ve $10 \mathrm{~kg}$ yük taşımaktadır. Tip $225 \mathrm{~cm}$ x $25 \mathrm{~cm}$ x $8 \mathrm{~cm}$ ebatlarında ve $5 \mathrm{~kg}$ yük taşımaktadır.

Fabrikanın, tam zamanında işleyişe uygun bir şekilde, haftalık ihtiyaca göre belirlediği, her ürüne ait boyuta göre kutu bilgisi kullanılarak Tablo 3'deki bilgiler elde edilmiştir. $\mathrm{Bu}$ tabloda şehir isimleri, her şehirde bulunan müşterilerin toplam ürün değişim talebi ve bu ürünler için gerekli kutuların haftalık ihtiyaç, miktarları gösterilmiştir.

Tablo 3. Müşterilerin fabrikadan beklediği haftalık bazda ürün değişim talebi

\begin{tabular}{|c|c|c|c|}
\hline Şehirler & $\begin{array}{c}\text { Tip 1 kutu } \\
\text { adedi / Hafta }\end{array}$ & $\begin{array}{c}\text { Tip 2 kutu } \\
\text { adedi / Hafta }\end{array}$ & $\begin{array}{c}\text { Toplam Kutu } \\
\text { Adedi / Hafta }\end{array}$ \\
\hline Kastamonu (1) & 60 & 40 & 100 \\
\hline Kocaeli (2) & 30 & 70 & 100 \\
\hline İstanbul (3) & 30 & 20 & 50 \\
\hline Samsun (4) & 25 & 20 & 45 \\
\hline Adana (5) & 30 & 45 & 75 \\
\hline Kayseri (6) & 35 & 25 & 60 \\
\hline Ankara (7) & 25 & 15 & 40 \\
\hline Sakarya (8) & 35 & 30 & 65 \\
\hline
\end{tabular}

\subsubsection{Araçlar}

Döngüsel dağıtım probleminde yükleme/boşaltma maliyetleri yüksek olmadığg sürece göz ardı edilir ve maliyetler araçlar üzerinden hesaplanmaktadır. Uygulamada 2 tip kamyonet kullanılmış olup, küçük ve büyük tip olarak ifade edilmiştir. Hangi araçtan kaç adet ihtiyaç duyulacağına problem çıktısında karar verilecektir.

Araçlar, ahşap kutuların uygun şekilde taşınabilmesi için özel bölümlendirmeler uygulanacaktır. Her bölüme iki tip kutu yerleştirilebilir, ancak her bölümde yalnız 1 kutu bulunabilir.

Tablo 4. Araç kapasiteleri

\begin{tabular}{|c|c|c|}
\hline Araçlar & Hacim & Kapasite \\
\hline Küçük Kamyonet & $6,7 \mathrm{~m}^{3}$ & $150 \mathrm{kutu}$ \\
\hline Büyük Kamyonet & $12,4 \mathrm{~m}^{3}$ & $250 \mathrm{kutu}$ \\
\hline
\end{tabular}




\subsection{Modelin Kurulması}

Döngüsel dağıtım problemlerinin çözümünde, Doğrusal Programlama (DP) tercih edilmektedir. Bu problem için kullanacağımız DP yardımıyla araç, rotalamada kısıtlar müşterilerden, araçlardan, fabrikadan ve müşteriler ile fabrika arasındaki bağlantılardan oluşacaktır. Modelimizde 9 şehir ve araçlar bulunmaktadır. 8 şehirde müşteri bulunmasına rağmen, modelde 9 şehir olarak ele alınmasının sebebi; fabrikanın, ilk müşteri olarak modelde yer edinmesidir. Araçlar rotaya ilk müşteri yani fabrikadan başlayarak, müşteri noktalarını ziyaret eder ve tekrar fabrikaya geri dönerler. Döngüsel dağıtım problemine özgü diğer kurallar şu şekildedir;

- A $\breve{g}$ içerisindeki rotaların sayısı kullanılan araçların sayısına eşittir.

- Bir araç, sadece bir rota üzerinde faaliyet gösterebilir.

- Rotalama yaparken ağ içerisindeki her bir müssteri, araçlardan sadece biri tarafindan ziyaret edilebilir.

- Aracın kapasitesi rota üzerinde bulunan tüm müşterilerin taleplerinin toplamından küçük ya da eşit olmalıdır. Bunun anlamı araçların kapasitelerinin üzerinde yüklenememesidir (Khan ve Siddiqui, 1998).

Temel rotalama problemlerinin modellenmesinden yola çıkılarak geliştirilen modelde, maliyeti düşük tutmak, dolayısıyla toplam kat edilecek yolun en düşük tutulması amaçlanmıştır. Geliştirilen modelde kullanılan indis, parametreler ve karar değişkenlerine yer verilmiştir.

Araç sayısı; iki tip araç için de ihtiyaç duyulabilecek adetlerden fazlası kadar tanımlanmış olup, model çıktısına göre alım gerçekleştirilecektir.

\section{İndisler}

a Şehir

b Şehir

k Araç

n Şehir sayıs1

\section{Parametreler}

Pab a ile $b$ şehirleri arasındaki mesafe 
Da a. şehirde değişimi yapılacak ürün miktarı

Ck k aracının kapasitesi

M Büyük bir sayı

Fk $\quad \mathrm{k}$ aracının $1 \mathrm{~km}$ yol katetmesi için gerekli yakıt ücreti

\section{Karar Değişkenleri}

Xabk $\mathrm{k}$ aracı a şehrinden $\mathrm{b}$ şehrine gittiyse 1 , gitmediyse 0

Tka $\quad \mathrm{k}$ aracıyla a noktasında değişimi yapılacak ürün miktarı

\section{Amaç Fonksiyonu}

Toplam maliyet bulunabilir.

$$
Z \min =\sum_{a}^{A} \sum_{b}^{B} \sum_{k}^{K}\left(X_{a b k} * P_{a b} * F_{k}\right)
$$

\section{Kisıtlar}

$\sum_{k}^{K} \sum_{b, b \neq a}^{B} X_{a b k}=1 \quad 1 \leq a, \forall a$

$\sum_{k}^{K} \sum_{a, a \neq b}^{A} X_{a b k}=1 \quad 1 \leq b, \forall b$

Her şehre bir kez uğranmalı.

$\sum_{b, b \neq a}^{B} X_{a b k}-X_{b a k}=0 \quad \forall a \forall k$

Bir şehre giren araç, o şehri terk etmeli.

$X_{a b k}+X_{b a k} \leq 1 \quad \forall a \forall b \forall k$

Gidilen yoldan geri dönülmemeli.

$\sum_{a}^{A} T_{k a} \leq M * \sum_{a, a \neq b}^{A} X_{b a k} \quad b=0, \forall k$

Rota fabrikada başlamalı.

$$
\sum_{a}^{A} T_{k a} \leq M * \sum_{a, b \neq a}^{A} X_{a b k} \quad b=0, \forall k
$$


Rota fabrikada bitmeli.

$T_{k a} \leq \sum_{b, b \neq a}^{B} X_{a b k} * M \quad \forall a \forall k$

Talebi karşılayacak kadar rota olmalı.

$T_{k a}=D_{a} * \sum_{a}^{A} X_{a b k} \quad \forall b \forall k$

Talep (değişimi yapılacak ürün) karşılanmalı.

$\sum_{a}^{A} T_{k a} \leq C_{k} \quad \forall k$

Taşınan miktar araç kapasitesini aşmamalı.

$X_{a b k}+\cdots+X_{n a k} \leq(n-1)$

Alt tur engelleme kısıtı. Araç rotalama probleminde uygun çözümün gerçekleşebilmesi için alt turların oluşmaması gerekmektedir. Çözüm sonucunda eğer alt tur oluşmuşsa alt tur engelleme kısıtları eklenmektedir. Problem eğer kısıtlayıcılar eklendiğinde de alt tur oluşmadan sonlanmazsa, tekrar dallara ayrilabilir ya da alt tur engelleme kısıtlayıcıları tekrar eklenerek alt turlar elimine edilebilir.

$$
\begin{aligned}
& X_{a b k} \in 0,1 \\
& 0 \leq T k a
\end{aligned}
$$

\subsection{Modelin Uygulanması}

Optimizasyonun sağlanması için toplam harcanan akaryakıt giderinin minimumda tutulmasını amaç, edinen doğrusal model çözüldüğü takdirde ürün değişim (toplama ve dağıtma) faaliyeti için gerekli araç, rotaları ve araç tipleri belirlenmiş olacaktır. Bu model için GAMS programı, CPLEX çözücüsü kullanılmıştır.

Modelin GAMS programında yazılışı Ek 1'de sunulmuştur.

\subsection{Uygulama Sonucu}

Önerilen matematiksel model "GAMS” ara yüzünde kodlanmış ve matematiksel model çözücüsü olarak “CPLEX 10.2” kullanılmıştır. En düşük toplam maliyeti 4528モ olarak 
Gonca, C. K. \& Gülsün, B.

bulmuştur. Çözüm sonucu ortaya çıkan rotalar, toplam yol, kapasiteler ve maliyet Tablo 5'de verilmiştir.

Tablo 5. Matematiksel model çözüm sonucu

\begin{tabular}{|c|c|c|c|c|c|c|}
\hline $\begin{array}{c}\text { Rota } \\
\text { No }\end{array}$ & $\begin{array}{c}\text { Araçlar } \\
\text { sayısı }\end{array}$ & Şehirler & $\begin{array}{c}\text { Toplam } \\
\text { Yol / } \\
\text { Haftalık }\end{array}$ & $\begin{array}{c}\text { Kullanılan } \\
\text { Kapasite }\end{array}$ & $\begin{array}{c}\text { Araç } \\
\text { Tipi }\end{array}$ & $\begin{array}{c}\text { Yol } \\
\text { Maliyeti / } \\
\text { Haftalık }\end{array}$ \\
\hline 1 & 5 & $\begin{array}{c}\text { Sakarya, Kocaeli, } \\
\text { Istanbul }\end{array}$ & $1437 \mathrm{~km}$ & $215 / 250$ & Büyük & $1.293 €$ \\
\hline 2 & 6 & $\begin{array}{c}\text { Ankara, Kastamonu, } \\
\text { Samsun }\end{array}$ & $2141 \mathrm{~km}$ & $185 / 250$ & Büyük & $1.927 £$ \\
\hline 3 & 1 & Kayseri, Adana & $2012 \mathrm{~km}$ & $135 / 150$ & Küçük & $1.308 €$ \\
\hline
\end{tabular}

Çözüm sonucunda 3 araç, seçilmiştir. 2 araç büyük kamyonet, 1 araç küçük kamyonettir. Toplam yol ise 5590 km' dir. Araçların rotaları Şekil 2'de gösterilmiştir.
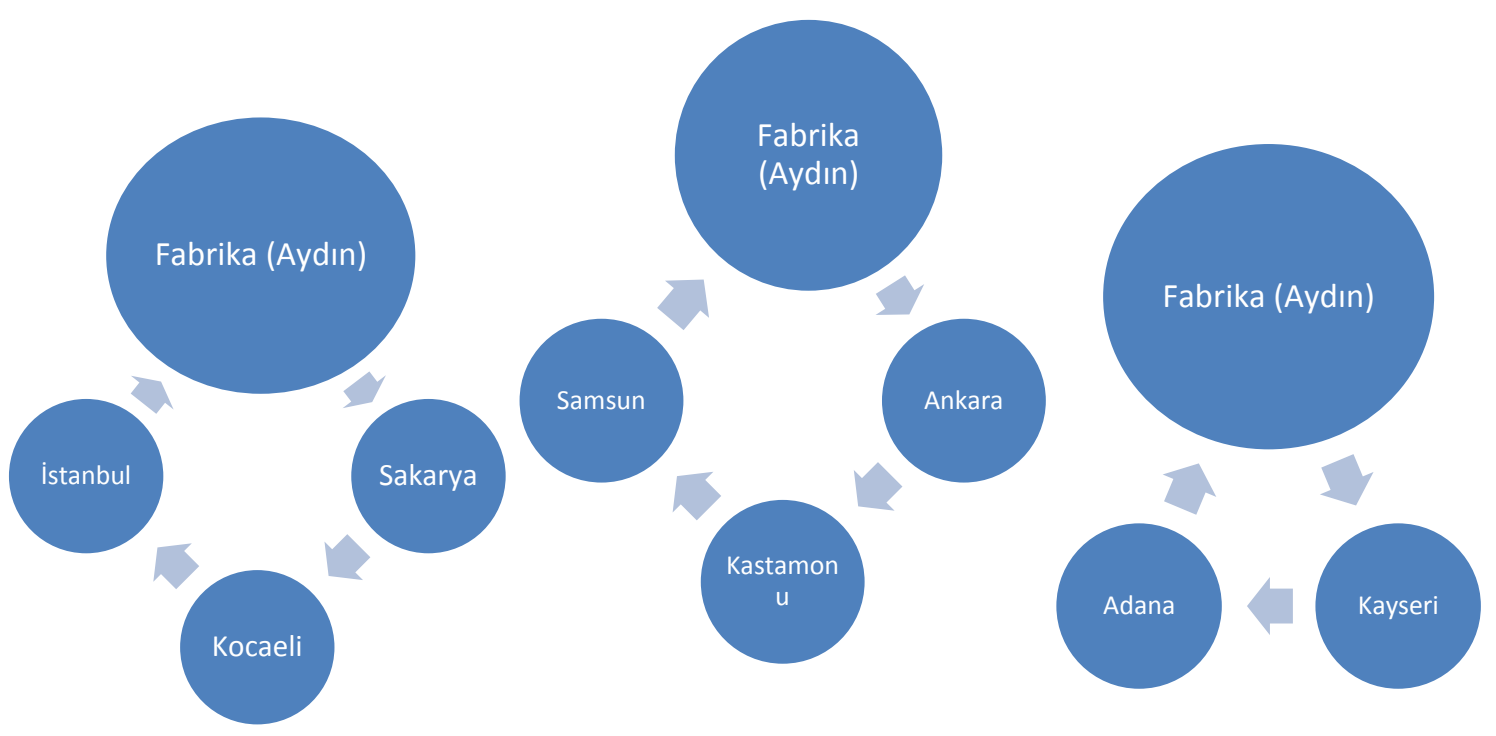

Şekil 2. Araçların izleyeceği rotalar

\section{Lojistik maliyeti}

Yeni model ile fabrika lojistik faaliyetlerini kendi bünyesinde alınacak olan araçlar ile yönetecektir. Bu durumda, bakım, kasko, trafik sigortası vb. giderler ve faaliyetleri kapsayan giderler toplamı araç amortisman gideri altında ele alınmıştır. Araç amortisman fiyatı, şoför giderleri, ayrıca araçların yakıt giderleri Tablo 6'da verilmiştir. 
Tablo 6. Lojistik maliyet kalemleri

\begin{tabular}{|c|c|c|}
\hline Gider/Araç & Küçük Kamyonet & Büyük Kamyonet \\
\hline Araç Amortisman/Hafta & $1.000 £$ & $1.300 €$ \\
\hline Şoför Giderleri/Hafta & $1.500 €$ & $1.500 €$ \\
\hline Yakıt/km & $0.65 €$ & $0.90 €$ \\
\hline
\end{tabular}

Lojistik faaliyetleri için harcanacak bu maliyet kalemleri sonrası, çözüm sonucu ortaya çıkan rotaların toplam maliyetleri ise Tablo 7'de verilmiştir.

Tablo 7. Rotaların toplam maliyeti

\begin{tabular}{|c|c|c|c|c|c|}
\hline $\begin{array}{c}\text { Rota } \\
\text { No }\end{array}$ & (Haftalık) & $\begin{array}{c}\text { Araç } \\
\text { Amortisman }\end{array}$ & $\begin{array}{l}\text { Yakıt } \\
\text { Bedeli }\end{array}$ & $\begin{array}{c}\text { Şoför } \\
\text { Giderleri }\end{array}$ & Toplam \\
\hline 1 & 5 & 1.300 至 & 1.293 E & $1.500 €$ & 4.093 E \\
\hline 2 & 6 & $1.300 €$ & $1.927 €$ & 1.500 至 & $4.727 €$ \\
\hline 3 & 1 & 1.000 E & 1.308 要 & $1.500 €$ & 3.808 E \\
\hline & Toplam & 3.600 E & $4.528 \equiv$ & 4.500 毛 & 12628 છ \\
\hline
\end{tabular}

\subsection{Mevcut ile Planlanan Durum Analizinin Kıyaslanması}

Mevcut durum ve yeni durum için haftalık maliyetler şehir bazlı olarak Tablo 8'de verilmiştir.

Tablo 8. Ürünlerin haftalık çevrimde yarattığı envanter maliyeti

\begin{tabular}{|c|c|c|c|}
\hline $\begin{array}{c}\text { Rota } \\
\text { No }\end{array}$ & Rota (Şehir) & $\begin{array}{c}\text { Mevcut Durum } \\
\text { Maliyeti } \\
\text { (Haftalı) }\end{array}$ & $\begin{array}{c}\text { Yeni Çözümde } \\
\text { Maliyet } \\
\text { (Haftalık) }\end{array}$ \\
\hline 1 & Sakarya, Kocaeli, İstanbul & $5.890 €$ & $4.093 €$ \\
\hline 2 & Ankara, Kastamonu, Samsun & $7.585 €$ & $4.727 €$ \\
\hline 3 & Kayseri, Adana & $5.295 €$ & $3 . .808 €$ \\
\hline & Toplam & $18.770 €$ & $12.628 €$ \\
\hline
\end{tabular}

Mevcut durum politikasına göre 3. parti kargo firmalarını kullanarak yapılan lojistik faaliyetlerinin haftalık maliyet toplamı 18.770 £'dir. Kargo firmaları yerine, fabrika bünyesine dahil edilecek lojistik operasyonunun kullanılması yeni yaklaşımı ile geliştirilen döngüsel sefer uygulamasında ise haftalık maliyet 12.628532 €’e indirilmiştir.

Haftalık taleplerinin yeni yaklaşımla lojistiğinin sağlanması durumunda, mevcut talepler göz önüne alındığında lojistik için yapılan harcamalarda \%33 lük bir iyileştirme 


\section{Gonca, C. K. \& Gülsün, B.}

sağlanmıştır. Ayrıca, mevcut rotada araçların \%83 kapasite ile çalıştığı göz önüne alınırsa, mevcut müşteri taleplerindeki olası artışta veya mevcut müşterilere yakın noktalarda oluşabilecek farklı müşterilerden yeni taleplerin gelmesinde birim lojistik maliyetlerinin daha da düşeceği göz önüne alınmalıdır.

\section{SONUC}

Bu makalede 1 numaralı giriş kısmında araç rotalama problemlerinin tanımı, örnekleri, önemi ve türlerinden bahsedilmiştir. 2 numaralı literatür kısmında ise, araç rotalama ve bu makaleye konu olan topla-dağıt rotalama tipi hakkında geçmişten günümüze yapılan tanımlamalara yer verilmiştir. 3 numaralı bölümde makaleye konu uygulamadan bahsedilmiş olup; endüstriyel bıçak bileme fabrikasında yapılan gözlemler hakkında bilgi verilmiş, uygulamanın amacından bahsedilmiş, müşteriler, ürünler ve araçlar tanıtılarak problem tanımı yapılmıştır. 3. bölümün devamında eş zamanlı topla-dağıt döngüsel dağıtım modeli problemine uygun olarak matematiksel model geliştirilmiş ve GAMS uygulaması üzerinde problem çözülmüştür. Devamında uygulamanın verdiği sonuçlar değerlendirilerek fabrikanın mevcut durumdaki lojistik maliyeti ile yeni sistem önerisindeki lojistik maliyeti kıyaslanmıştır. $\mathrm{Bu}$ uygulama, lojistik faaliyetlerinin fabrika bünyesinde yürütülmesinin yüksek tasarruf sağladığını göstermiştir.

\section{REFERENCES / KAYNAKLAR}

Atmaca, E. (2012). Bir kargo şirketinde araç rotalama problemi ve uygulaması. Tübav Bilim Dergisi, 5(2), 12-27.

Bayrak, A. \& Özyörük, B. (2017). Bölünmüş talepli eş zamanlı topla dağıt araç rotalama problemi için karşılaştırmalı matematiksel modeller. Gazi Üniversitesi Mühendislik-Mimarlık Fakültesi Dergisi, 32(2), 469-479.

Casco, D. O., Golden, B. L. \& Wasil, E. A. (1988). Vehicle routing with backhauls: Models, algorithms, and case studies. In Golden, B. L. \& Assad, A. A. (Eds.), Vehicle Routing: Methods and Studies (pp. 127-147). Amsterdam: North-Holland.

Çetin, S. \& Gencer, C. (2010). Kesin zaman pencereli eş zamanlı dağıtım toplamalı araç rotalama problemi: Matematiksel model. Gazi Üniversitesi Mühendislik-Mimarlık Fakültesi Dergisi, 25(3), 579-585.

Dantzig, G. B. \& Ramser, J. H. (1959). The truck dispatching problem. Management Science, 6(1), 80-91.

Dethloff, J. (2001). Vehicle routing and reverse logistics: The vehicle routing problem with simultaneous delivery and pick-up. OR-Spektrum, 23(1), 79-96.

Düzakın, E. \& Demircioğlu, M. (2009). Araç rotalama problemleri ve çözüm yöntemleri. Çukurova Üniversitesi Íktisadi ve Ídari Bilimler Fakültesi Dergisi, 13(1), 68-87. 
Göksal, F. P., Karaoğlan, İ. \& Altıparmak F. (2013). A hybrid discrete particle swarm optimization for vehicle routing problem with simultaneous pickup and delivery. Computers \& Industrial Engineering, 65(1), 39-53.

Karaoğlan, İ. (2009). Dă̆ıtım ağları tasarımında yer seçimi ve eşzamanlı topla-dăğt araç rotalama problemleri (Doktora tezi). Gazi Üniversitesi, Ankara.

Khan, M. S. \& Siddiqui, A. S. (1998). The radius method: A modified heuristic for the vehicle routing problem. Department of Industrial Engineering and Operations Research University of California Berkeley.

Min, H. (1989). The multiple vehicle routing problem with simultaneous delivery andpick-up points. Transportation Research Part A: General, 23(5), 377-386.

Min, H., Current, J. \& Schilling, D. (1992). The multiple depot vehicle routing problem with backhauling. Journal of Business Logistics, 13(1), 259-288.

Nagy, G. \& Salhi, S. (2005). Heuristic algorithms for single and multiple depot vehicle routing problems with pickups and deliveries. European Journal of Operational Research, 162(1), 126-141.

Salhi, S. \& Nagy, G. (1999). A cluster insertion heuristic for single and multiple depot vehicle routing problems with backhauling. Journal of The Operational Research Society, 50(10), 1034-1042.

Tang, F. A. \& Galvao, R. D. (2002). Vehicle routing problems with simultaneous pick-up and delivery service. Opsearch, 39(1), 19-33.

Toth, P. \& Vigo, D. (2002). The vehicle routing problem. ABD: Society for Industrial and Applied Mathematics.

Yazgan, H. R. \& Büyükyılmaz, R. G. (2017). Eş zamanlı topla dağıt araç rotalama problemine sezgisel bir çözüm yaklaşımı. Sakarya Üniversitesi Fen Bilimleri Enstitüsü Dergisi, 22(2), 436-449.

Yürek, S. S. (2012). Bir otomotiv fabrikasında ürünlerin tedarikçilerinden döngüsel sefer uygulaması ile toplanması problemi (Yüksek lisans tezi). Gazi Üniversitesi, Ankara. 
Gonca, C. K. \& Gülsün, B.

\section{EK 1}

Sets

$\mathrm{ab} / 0 * 8 /$

$\mathrm{k} / 1 * 8 /$

Alias (ab,a,b)

scalars M /10000/;

Parameters

c(k) /1 125,2 125,3 125,4 125, 5 250,6 250, 7 250,8 250/

d(a) / 0 0,1 100,2 100,3 50,4 45,5 75,6 70,7 40,8 65 /

$\mathrm{f}(\mathrm{k}) / 1$ 0.65, 2 0.65, 3 0.90, 4 0.90/;

$\begin{array}{llllllllll} & 0 & 1 & 2 & 3 & 4 & 5 & 6 & 7 & 8 \\ 0 & 0 & 844 & 573 & 684 & 1018 & 874 & 830 & 597 & 605 \\ 1 & 844 & 0 & 396 & 507 & 290 & 683 & 453 & 236 & 359 \\ 2 & 573 & 396 & 0 & 111 & 623 & 837 & 663 & 342 & 37 \\ 3 & 684 & 507 & 111 & 0 & 734 & 948 & 774 & 453 & 148 \\ 4 & 1018 & 290 & 623 & 734 & 0 & 721 & 453 & 413 & 586 \\ 5 & 874 & 683 & 837 & 948 & 721 & 0 & 335 & 492 & 800 \\ 6 & 830 & 453 & 663 & 774 & 453 & 335 & 0 & 335 & 626 \\ 7 & 597 & 236 & 342 & 453 & 413 & 492 & 335 & 0 & 305 \\ 8 & 605 & 359 & 37 & 148 & 586 & 800 & 626 & 305 & 0\end{array}$

Positive variables $\mathrm{t}(\mathrm{k}, \mathrm{a})$;

Binary Variables $\mathrm{x}(\mathrm{a}, \mathrm{b}, \mathrm{k})$;

Variable z;

Equations

amac

ugrama1(a)

ugrama2(b)

$\operatorname{gircik}(a b, k)$ 
donmeme $(\mathrm{a}, \mathrm{b}, \mathrm{k})$

fabrikabasla(k)

fabrikabitir(k)

$\operatorname{talep}(\mathrm{k}, \mathrm{a})$

rotasayisi $(k, a)$

kapasite(k)

;

amac.. $\mathrm{z}=\mathrm{e}=\operatorname{sum}((\mathrm{a}, \mathrm{b}, \mathrm{k}) \$(\operatorname{ord}(\mathrm{a})$ ne ord(b)),x(a,b,k)*p(a,b)*f(k));

ugrama1(a) $\$(\operatorname{ord}(a) \operatorname{ge} 1) . . \operatorname{sum}(k, \operatorname{sum}(b \$(\operatorname{ord}(b) \operatorname{ne} \operatorname{ord}(a)), x(a, b, k)))=e=1$;

ugrama2(b) $\$(\operatorname{ord}(b)$ ge 1).. $\operatorname{sum}(\mathrm{k}, \operatorname{sum}(\mathrm{a} \$(\operatorname{ord}(\mathrm{a}) \operatorname{ne} \operatorname{ord}(\mathrm{b})), \mathrm{x}(\mathrm{a}, \mathrm{b}, \mathrm{k})))=\mathrm{e}=1$;

$\operatorname{gircik}(a b, k) . . \operatorname{sum}(a, x(a, a b, k))=e=\operatorname{sum}(b, x(a b, b, k))$;

donmeme $(\mathrm{a}, \mathrm{b}, \mathrm{k}) \$(\operatorname{ord}(\mathrm{a})$ ne ord $(\mathrm{b})) . . \mathrm{x}(\mathrm{a}, \mathrm{b}, \mathrm{k})+\mathrm{x}(\mathrm{b}, \mathrm{a}, \mathrm{k})=\mathrm{l}=1$;

fabrikabasla(k).. sum(b $\$(\operatorname{ord}(\mathrm{b})$ ne 0$), x(" 0 ", b, k)) * M=g=\operatorname{sum}(b, t(k, a))$;

fabrikabitir(k).. sum(a $\$(\operatorname{ord}(a)$ ne 0$), x(a, " 0 ", k))^{*} M=g=\operatorname{sum}(b, t(k, a))$;

rotasayisi(k,a)\$(ord(a) ge 1).. $\operatorname{sum}(\mathrm{b} \$(\operatorname{ord}(\mathrm{a}) \text { ne } \operatorname{ord}(\mathrm{b})), \mathrm{x}(\mathrm{a}, \mathrm{b}, \mathrm{k}))^{*} \mathrm{M}=\mathrm{g}=\mathrm{t}(\mathrm{k}, \mathrm{a})$;

talep $(k, a) . . t(k, a)=e=d(a) * \operatorname{sum}(b, x(a, b, k))$;

kapasite(k).. $\operatorname{sum}((\mathrm{a}), \mathrm{t}(\mathrm{k}, \mathrm{a}))=\mathrm{l}=\mathrm{c}(\mathrm{k})$;

Model makale /all/;

Solve makale using mip minimizing z;

Display x.1,x.m; 